\title{
Expert Meeting Report: Transforming Existing Buildings through New Media - An Idea Exchange
}

Stacy Hunt

Building America Retrofit Alliance (BARA) 


\begin{abstract}
NOTICE
This report was prepared as an account of work sponsored by an agency of the United States government. Neither the United States government nor any agency thereof, nor any of their employees, subcontractors, or affiliated partners makes any warranty, express or implied, or assumes any legal liability or responsibility for the accuracy, completeness, or usefulness of any information, apparatus, product, or process disclosed, or represents that its use would not infringe privately owned rights. Reference herein to any specific commercial product, process, or service by trade name, trademark, manufacturer, or otherwise does not necessarily constitute or imply its endorsement, recommendation, or favoring by the United States government or any agency thereof. The views and opinions of authors expressed herein do not necessarily state or reflect those of the United States government or any agency thereof.
\end{abstract}

Available electronically at http://www.osti.gov/bridge

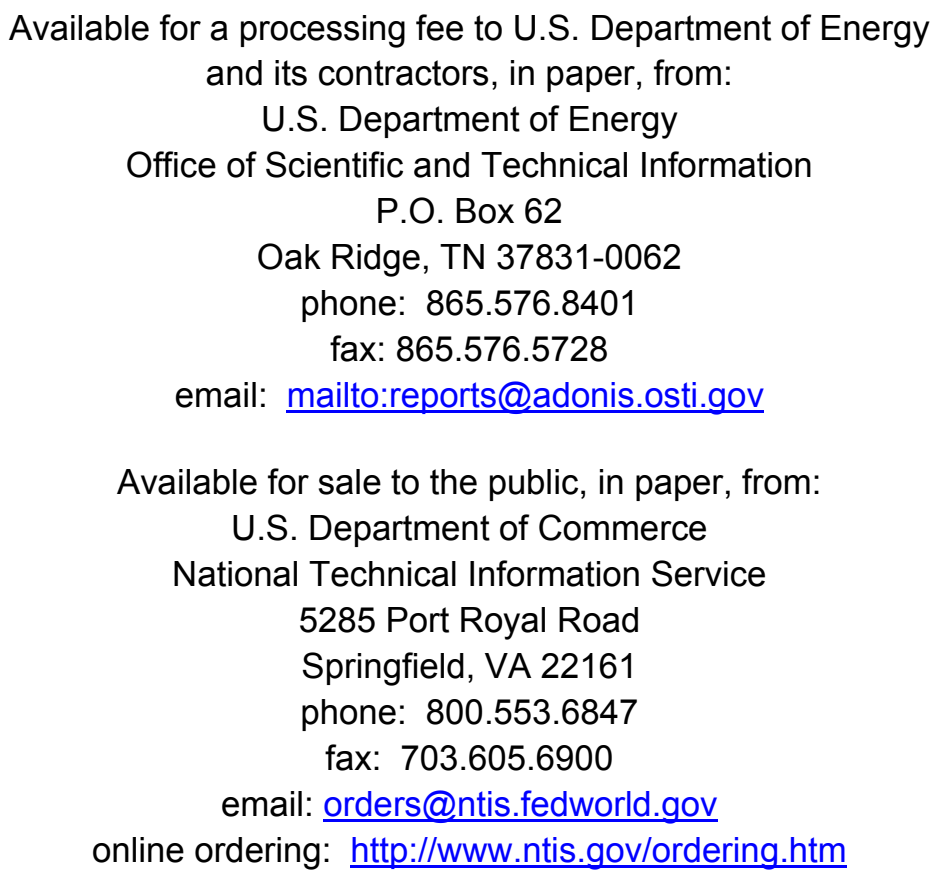

Printed on paper containing at least $50 \%$ wastepaper, including $20 \%$ postconsumer waste 


\title{
Expert Meeting Report:
}

\section{Transforming Existing Buildings through New Media: An Idea Exchange}

\author{
Prepared for: \\ Building America \\ Building Technologies Program \\ Office of Energy Efficiency and Renewable Energy \\ U.S. Department of Energy
}

Prepared by:

Stacy Hunt

Building Media and the Building America Retrofit Alliance (BARA)

4301 Lancaster Pike, Bldg. 721

Wilmington, DE 19805

NREL Technical Monitor: Cheryn Engebrecht

Prepared under Subcontract No. KNDJ-0-40336-02

May 2012 
[This page left blank] 


\section{Contents}

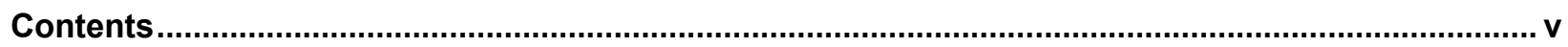

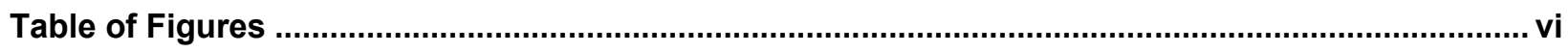

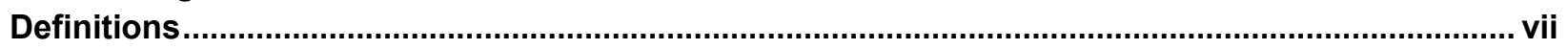

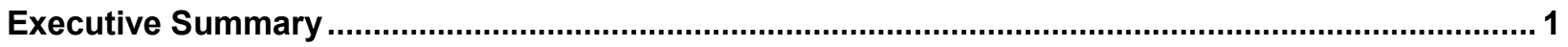

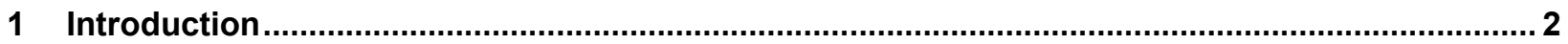

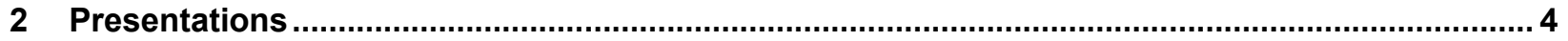

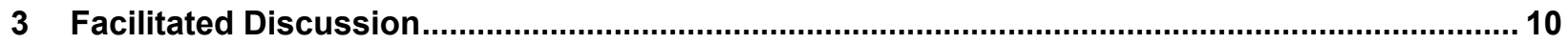

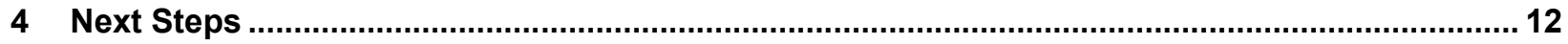




\section{Table of Figures}

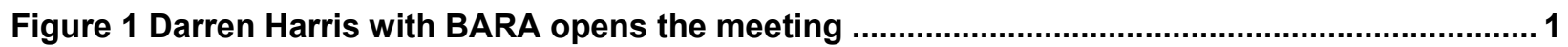

Figure 2 Tom White presents the Home Energy Pros website.................................................... 5

Figure 3 Deane Evans with BARA facilitates the afternoon discussion .......................................... 10

Unless otherwise noted, all figures were created by the BARA team. 


\section{Definitions}

AF

AMC

AMI

ASB

ARRA

AQB

BIRA

BPI

CEAD

CEQ

CBPCA

CMA

DEER

DOE

DSIRE

DTI

EE

EECBG

EEM

EIM

EGIA

ESCO

Fannie Mae

FI

FICO

FHA

Freddie Mac

GHG

GREEN

HERS

HPwES

HUD

ICLEI

LEED

LCC

OBF

OEM

OREA

MAI

NAR

NAREA

PG\&E

PACE

PCBC

PPA

PV

RESNET

SAVE

USPAP
Appraisal Foundation

Appraiser Management Companies

Area Median Income

Appraisal Standards Board

American Recovery and Reinvestment Act of 2009

Appraiser Qualifications Board

Building Industry Research Alliance

Building Performance Institute

Clean Energy Assessment District

White House Council on Environmental Quality

California Building Performance Contractors Association

Comparative Market Analysis

Database for Energy Efficient Resources

U.S. Department of Energy

Database of State Incentives for Renewables \& Efficiency

Debt to Income

Energy Efficiency

Energy Efficiency and Conservation Block Grants

Energy Efficient Mortgage

Energy Improvement Mortgage

Electric \& Gas Industries Association

Energy Service Company

Federal National Mortgage Association (FNMA)

Financial Institution

Fair Isaac Corporation (a credit rating agency)

Federal Housing Authority

Federal Home Loan Mortgage Corporation (FHLMC)

Greenhouse Gas

Green Resources for Energy Efficient Neighborhoods Act

Home Energy Rating System

Home Performance with ENERGY STAR $\mathbb{}$

U.S. Department of Housing and Urban Development

International Council for Local Environmental Initiatives - Local Governments for Sustainability

Leadership in Energy and Environmental Design

Life Cycle Cost

On-Bill Financing

Office of Energy Management

CA Office of Real Estate Appraiser

Member of the Appraisal Institute

National Association of Realtors

National Association of Real Estate Appraisers

Pacific Gas \& Electric

Property-Assessed Clean Energy

Pacific Coast Builders Conference

Power Purchase Agreement

Photovoltaic

Residential Energy Services Network

Sensible Accounting to Value Energy Act

Uniform Standards of Professional Appraisal Practice 


\section{Executive Summary}

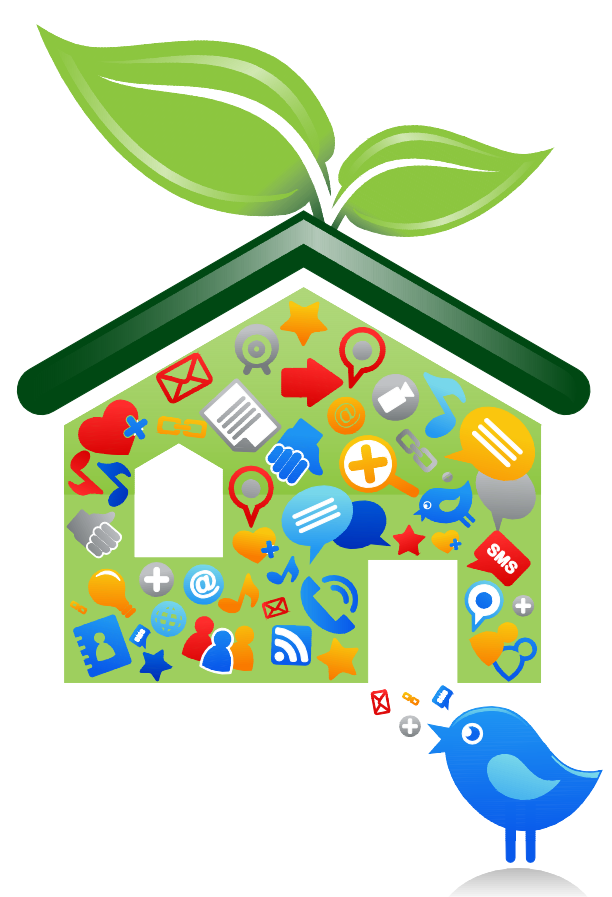

The Building America expert meeting, Transforming Existing Buildings through New Media: An Idea Exchange was hosted by the Building America Retrofit Alliance (BARA) on September 13, 2011, at the Green Valley Ranch in Las Vegas, Nevada. This meeting provided a forum for presentations and discussions on the use of new media to work with remodelers and retrofit projects to improve energy efficiency and deliver research results from the Building America program to remodelers.

During this meeting, BARA brought together experts in the areas of networked communications, technology, education, and traditional and new media to explore opportunities to transform the remodeling industry and radically improve residential energy performance in the next decade through new media strategies.

This report presents a brief background on the topics, meeting objectives, logistics, presentations, gaps and barriers, and next steps.

Eight presentations were given discussing different types and uses of new media that impact the U.S. residential remodeling industry. The meeting was attended by 30 outside participants with expertise in the areas of traditional and new media, technology, education, outreach program development, utility-based programs, residential financing, and energy efficiency research.

The key outcome of the meeting was identifying that the most critical challenge in

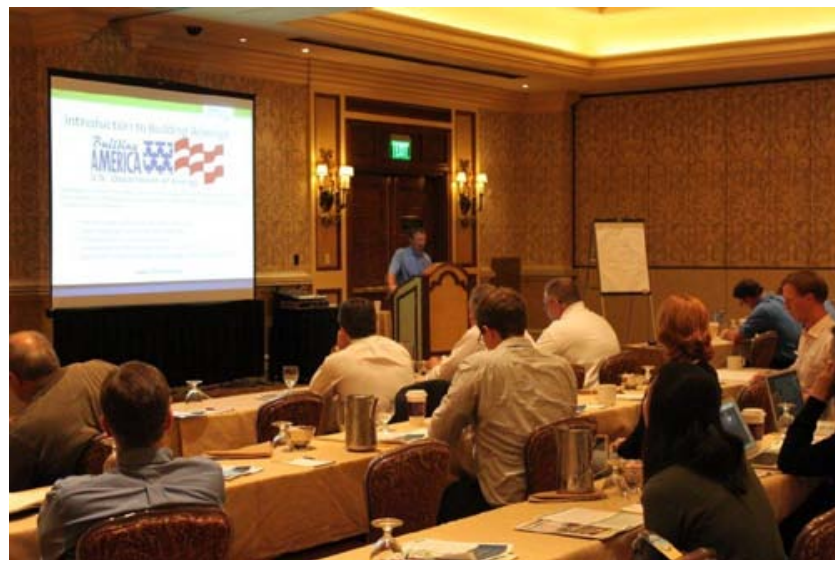

Figure 1. Darren Harris with BARA opens the meeting transforming the residential retrofit market with media is not the technology, but the content and effective outreach strategies needed to develop packages of useful information accessible to many partners and audiences.

The issue of motivation was also repeatedly raised during the discussion. Why should remodelers care about providing more energy efficient results if the clients don't want it or ask for it? Attendees expressed that remodelers won't push if clients don't pull on this issue. Further, how can remodelers create pull from the client and how can new media help with that effort? 


\section{Introduction}

New media - from social networks to online, on-demand training to apps and games - is transforming learning, and working across the country at a rapidly accelerating pace. The "new" in new media constantly shifts. Fifteen years ago, the Internet, which gave us hypertext as a way to "drill down" and explore non-linear modes of learning, was completely new. Since then, the forms of online media have grown increasingly dynamic, incorporating video, animation, and sound in ways that have profoundly enhanced the visual and aural literacy of the world's wired populace. With digital video and photography as a primary mode of capture and the Internet as a means of distribution, the ability to record and communicate visual data is now accessible to anyone, regardless of age or background, instantaneously. This alone has transformed society at every level, including the designers, builders, and remodelers of America's housing stock. None of us could work the way we do today without online technologies, and the advancement of the use of technology in everyday life, both work and personal, is not slowing its pace.

The Building America Retrofit Alliance (BARA) team recognizes that emerging online technologies offer new opportunities to the U.S. Department of Energy's (DOE) Building America program, providing a way not only to deploy project research results to the public, but also as a means of gathering data from a much broader range of active building projects than may not otherwise have been feasible.

BARA convened the Transforming Existing Buildings through New Media: An Idea Exchange expert meeting of thought leaders in the field of multimedia content delivery to better understand how new media might be used to transform the energy efficiency of existing buildings.

The goal was to explore, in a relatively free-ranging forum, what the new media landscape looks like going forward and how that might impact how the residential retrofit industry works, learns, and adopts new methods and technologies.

\subsection{Purpose}

This expert meeting was used as a strategic planning tool for BARA to facilitate an open forum discussion among industry leaders and traditional and new media outreach and development partners on strategies to transform energy efficiency in existing homes using new media. BARA will use information from the expert meeting to enhance research and outreach efforts with traditional and new media partners and with the remodeling industry. It is hoped that this meeting created an ongoing opportunity to collaborate with our partners and colleagues as we explore new options to transfer research results from the Building America program to the market.

\subsection{Objectives}

- Review Building America's focus and renewed interest in translating research results to the market.

- Enhance Building America researchers' understanding of traditional and new media strategies and tools. 
- Identify opportunities to utilize or test new media strategies to communicate research results.

- Characterize research priorities as they relate to developing and implementing effective outreach programs to communicate research results.

- Identify opportunities for collaboration with traditional and new media partners.

\subsection{Location and Date}

The Transforming Existing Buildings through New Media: An Idea Exchange expert meeting was held at Green Valley Ranch Resort in Las Vegas, Nevada, in conjunction with the Energy and Environmental Building Alliance's Excellence in Building Conference. The meeting was hosted on the day prior to the opening of the conference to ensure the attendees would have an opportunity to visit the events and exhibits offered.

$\begin{array}{ll}\text { Date: } & \text { Tuesday, September 13, } 2011 \\ \text { Time: } & \text { 9:00am to 5:00pm } \\ \text { Location: } & \text { Green Valley Ranch } \\ & \text { La Cascada I \& II } \\ & \text { 2655 S Rainbow Blvd } \\ & \text { Las Vegas, NV 89146 }\end{array}$

\subsection{Participating Experts}

Participants in the meeting included industry experts from Building America, traditional and new media outlets, utility-based programs, national laboratories, U.S. Department of Energy, Environmental Protection Agency, residential remodelers and contractors, financing programs, and related organizations. The following groups were represented at the meeting:

\begin{tabular}{|l|l|}
\hline Better Building Performance & NAHB Research Center \\
\hline Building Media & National Renewable Energy Laboratory (NREL) \\
\hline C\&O Conservation Inc. & New Jersey Institute of Technology \\
\hline Certainteed & Newport Ventures, Inc. \\
\hline Confluence Communications & Pacific Northwest National Laboratory \\
\hline ConSol & Panasonic Home \& Environment Company \\
\hline Crocus Mill Associates & Pentair \\
\hline Davis Energy Group & R. Pelton Builders, Inc. \\
\hline DuPont Building Innovations & Real Estate Mortgagee Network \\
\hline Home Energy & RESNET \\
\hline HomeFree Nevada & SIPS \\
\hline IBACOS & Southwest Energy Efficiency Project \\
\hline Interplay Energy & Steven Winter Associates, Inc. \\
\hline iShow Media & Structural Insulated Panel Association \\
\hline K\&H & Taunton \\
\hline KataLabs & U.S. Department of Energy \\
\hline LaHouse Resource Center & U.S. Environmental Protection Agency \\
\hline Mark Johnson \& Associates & \\
\hline
\end{tabular}




\section{Presentations}

Nine qualified industry experts provided 20-minute presentations on specific case studies showing their experience and opinions of developing and using new media. Presenters focused both on strategies outside and within the remodeling industry. After presentations were complete, BARA led participants in an afternoon discussion session.

Presenters included:

- Building America Retrofit Alliance: Darren Harris, Overview and Introductions

- OurBricks.com: Henrik Bennetsen, Exploring Collaborative Work in 3-D Environments

- Home Energy Magazine,:Tom White, Online Communities for Creating Change

- K\&H ISG: Brandon J. Ackley and John Metselaar, Using Research to Develop an Integrated Marketing Strategy

- Building Media: Clayton DeKorne, Using 3-D Interactive Technology for Building Science Education

- Mark Johnson, Social and Virtual Media Marketing for the Building Industry

- Taunton: Dan Morrison, Delivering Information Effectively Using Multimedia Tools

- Interplay Energy: Stephen Quirk, Training Simulation in Action - Case Study Phase 1

\subsection{Introductory Presentation - Darren Harris, Building America Retrofit Alliance}

Presenter Bio: Darren has more than 15 years experience in marketing, business development and public relations in the building products industry. His experience overseeing operations for a startup media company, his expertise creating and developing online demonstration projects, and his skill in forming partnerships with government agencies, building product manufacturers and associations makes him a valuable resource.

Darren Harris of BARA welcomed the attendees to the expert meeting with a brief overview presentation focused on the goals and objectives of the Building America program and BARA and the objectives and intended outcomes of the meeting. Darren pointed out six "innovation stations" set up in the rear of the room for attendees to explore during breaks.

\subsection{Exploring Collaborative Work in 3-D Environments}

Presenter Bio: Henrik Bennetsen cofounded Katalabs back in early 2010 as a spinoff from Stanford research. Katalabs created OurBricks, which leverages HTML5 technology to connect people who need 3-D content with those who can create it. In the process of doing these things, he has founded or contributed to a range of open source projects.

Henrik Bennetsen with KataLabs presented on strategies to create 3-D communities through the use of Web innovations, focused on open standards that allow people to engage with 3-D modeling strategies. Included in his main points of discussion: 
- Internet is only 20 years old.

- Evolution of the medium: the Web has become a reflection of itself instead of other mediums forced into the Web.

- KataLabs is trying to create tools for people to use to create 3-D content - a basic toolbox to allow anyone to create 3-D visualizations. He refers to creating Legos that everyone can build with, no matter their skill level. He also likened the new tools for 3-D content to creating music, using the example of employing a live cellist versus having music sampling, enabling anyone to access to a full orchestra.

- Kataspace, a simple Web-based application built on the Sirikata platform, is removing the "friction access" from the process of online collaboration; no need for software downloads or plug-ins, but the seamless communication among different software allowing for the seamless collaboration among users.

Key takeaways:

Technology is becoming more accessible because of advancements like those on which KataLabs is working.. The "Internet medium" is becoming a palette on which anyone can create tools, no matter their skill level in website or software development. 3-D modeling tools are advancing quickly and their use in the building community will only become easier. Systemsapproach modeling will become simpler as "Lego-like" components fill online libraries.

\subsection{Online Communities for Creating Change}

Presenter Bio: Tom White has over 20 years' experience in managing and consulting to nonprofit, academic, and for-profit publishers, including Greater Good magazine, the Whole Earth Review, University of California Press, Pacific News Service, California Coast \& Ocean, and Bay Nature magazines. Tom is the publisher of Home Energy Magazine and also edits and publishes the Social Enterprise Reporter, an online newsletter for social entrepreneurs.

Tom White, with Home Energy

Magazine/Home Energy Pros (HEP), talked about the development of the HEP website as a case study in using the Internet and social media to drive energy efficiency in housing messaging to a broad community.

- The intent of Home Energy Savers and HEP site was to create a community that allows professionals to come together to access information on energy efficiency.

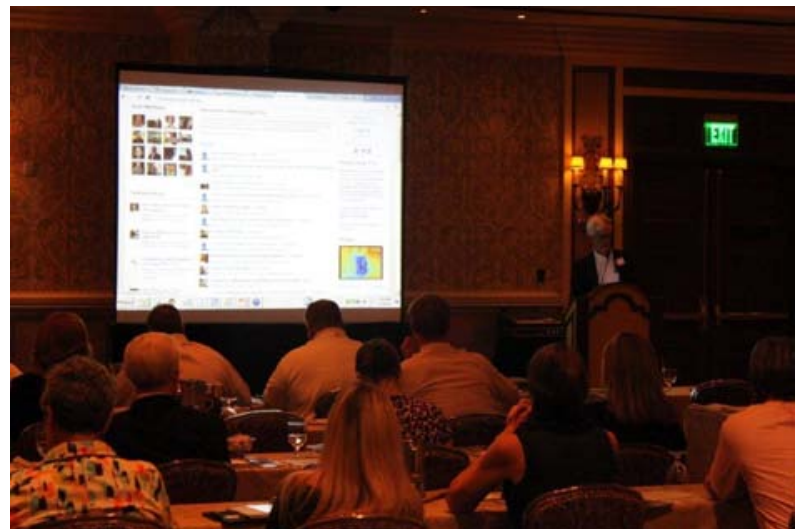

Figure 2. Tom White presents the Home Energy Pros website. Photo printed with permission.

- Membership is growing: $54 \%$ joined in first 2 months after the launch in November 2010 and there has been 5\% growth per month. 
- The site is free and they do not sell advertising. Two-thirds of users are referred by Google with a total of 55,000 viewers since launch with 7,500 unique viewers per month.

- Forums on the site allow many different audiences to chime in and comment on new technologies and strategies as well as for people to gain valid feedback. Video is easy to add to the site and a lot of content is shared by users.

- The site's popular "Hall of Shame" allows users to post mistakes and get input from others.

- About $20 \%$ of users are active community users and others are all reading and viewing other people's posts (typical of these sites).

- HEP Twitter feed has more than 8,500 followers. The Facebook page wasn't terribly successful.

Key takeaways:

The infrastructure of HEP allows for transfer of information to a key market. Varying contributors throughout the home energy performance industry keeps information fresh and provides opportunities to cross-pollinate messages and content. The flexibility of the site allows the format to be tailored to the content. For example, training can be delivered via video, while project-specific photos can be posted for other members to comment on. Partnerships with thought leaders have been critical in building the community of users for HEP, which could be a useful model for a building science online community.

\subsection{Using Research to Develop an Integrated Marketing Strategy}

Presenter Bios: Brandon J. Ackley has focused on staff growth and retention through development, corporate acquisition, national sales, production and operational workflow, profitability analytics, and division management at K\&H Integrated Print Solutions. Brandon has also been the Logistics Manager and Workflow Analyst, investing time in furthering lean practices for $K \& H$.

John Metselaar is the Chief Integrated Marketing and Creative and Brand Strategist at K\&H ISG (Integrated Solutions Group). John has excelled at Integrated (Traditional to Online) Direct Response Marketing, Branding, Creative Services, and eCommerce since 1995. He pioneered online marketing and advertising in 2000 by creating a perpetual testing environment supported with real-time tracking technology for measuring performance.

Brandon Ackley talked about the background of the company and utilized Renewals by Andersen (windows) as a case study showing the use of integrated marketing strategies. The presentation focused on the use of metrics and measurements to evaluate communication strategies and to target specific materials to create success.

Key takeaways:

Demographic profiling and geographic targeting have been very successful strategies to create best practices to reach audiences. Imagery and messages must target region and audience appropriately and content must be compelling. Traditional media and distribution (e.g. door hangers, direct mail) often trumped new media. 


\subsection{Using 3-D Interactive Technology for Building Science Education}

Presenter Bio: As an instructional-design specialist for Building Media, Inc. (BMI), Clayton DeKorne is currently managing the content development team working on energy code training for the California Energy Commission (CEC) and New York State Energy Resources Development Authority (NYSERDA), and on weatherization training for the U.S. Dept. of Energy's National Training \& Education Resource (NTER). Prior to working with BMI, Clayton was a carpenter in Burlington, Vermont, for 11 years, and senior editor of the Journal of Light Construction for 10 years. He obtained a Master in Education in Curriculum Design in 2001 and served as a producer for the New York Times Learning Network from 1999 to 2003.

Clayton DeKorne focused on strategies to use 3-D interactive gaming technology for building science education. He presented a case study where BMI is working with the National Institute of Building Science (NIBS) and collaborating with eight different companies on a research project to create an open source platform for the development of interactive, game-based building-science training. Specifically, he demonstrated a blower door testing gaming scenario that is part of a larger program teaching building diagnostics.

Key takeaways:

- To a remodeling contractor, the Internet is a bunch of individual, often unrelated pieces.

Strategies that provide better integration and more of a one-stop-shop presentation will be critical to delivering content to the remodeling audience. Stand-alone, immersive environments can help supplement a lack of field training.

- Because energy retrofits to existing buildings involves physical work, the Internet cannot be a complete training solution. But it can effectively provide training support in a blended learning environment. It works especially well as a platform to demonstrate work as it should be done in the field and help learners visualize the invisible (e.g. see energy and moisture transfer through buildings).

\subsection{Social and Virtual Media Marketing for the Building Industry}

Presenter bio: Mark Johnson is a recognized leader in the building products and design industry for his career as a marketer/architect/educator/speaker. He is a FAIA architect, AIBD Professional Building Designer, and NKBA Certified Kitchen Designer (CKD).

Mark Johnson talked about using social media as an overlay to marketing, focusing on his experiences working with Whirlpool and MASCO over the past 10 years. He pointed out that social media is becoming less social and more business-like and formal. Mark talked about converting social media to relationships and influence, building brand loyalty through social media plus live venues, engaging professionals through virtual media, and a new language of designing, building, and measuring the results through social media metrics. Mark showed case studies from KBIS 2010, AIA 2012, SEBC 2010, Google 3-D Basecamp, and others. Key takeaways:

- The previous hierarchy of messaging has collapsed: we are no longer broadcasters. Rather, we are now part of the community we wish to inform. 
- It is critical to uncover the voices that define and steer your markets and capture their efforts.

- Everything Mark undertook for these efforts was free.

\subsection{Delivering Information Effectively Using Multimedia Tools}

Presenter bio: Daniel Morrison has built and remodeled houses in Montana, New Mexico, Texas, Tennessee, Maine, and Massachusetts. After six years as an editor at Fine Homebuilding magazine, Dan was asked to jump in to building GreenBuildingAdvisor.com. He is senior Web producer for both Green Building Advisor and FineHomebuilding.com.

Dan Morrison presented on his experience with Fine Homebuilding and Green Building Advisor and focused on the need to deliver information effectively through a variety of mediums. Dan showed strategies used by both the magazine and the website to properly capture and deliver information in the most useful manner for the audience. This involved a variety of media. He pointed out that a mix of information strategies is critical - photos, illustrations, words, video, interactivity — and that using one and not the other excludes some portion of your audience. Dan offered, "A one page, well-written, and well-organized Word document is going to be way more effective than a lovely flash medium that isn't well thought out. Garbage in, garbage out. All mediums have limitations and opportunities."

Key takeaways:

- It is critical to allow content to drive medium, instead of the other way around.

- Use whatever it takes to properly explain and nothing more.

- Content development strategies can be effectively integrated so that one effort to gather content can be used across many mediums.

- Simplicity rules.

- Content capture and creation can start at video and work it's way back to print - an upside down model.

\subsection{Training Simulation in Action - Case Study Phase 1}

Presenter bio: Most recently, Stephen Quirk was Senior Vice President of Greener Dawn Residential where he was responsible for product development. Prior to joining Greener Dawn Residential, he served as Senior Research Analyst in the Greener Dawn Investment Group, where he covered the solar, bio-fuel, and energy efficiency markets.

Stephen Quirk showed a 3-D simulation that Interplay Energy has developed for weatherization training, specifically on combustion safety. He presented the simulation, which can be delivered over the Web without need for software downloads. 
Key takeaways:

- Technology now allows the development and delivery of interactive simulation and game-based training with relative ease and cost effectiveness, compressing training times while offering increased experiential knowledge without the costs of field training.

- Game-based training can enhance and reinforce field training, but field training is still key. 


\section{Facilitated Discussion}

The facilitated discussion began with a recap of the key points of the morning's presentations. The comments centered on three major themes, listed below. In some cases, comments could be categorized under more than one theme. For the purpose of this report, the comments have been organized by the primary thrust of the participant's idea.

HOW TO SELL IT: How remodelers can sell energy efficiency or create pull for it from their clients.

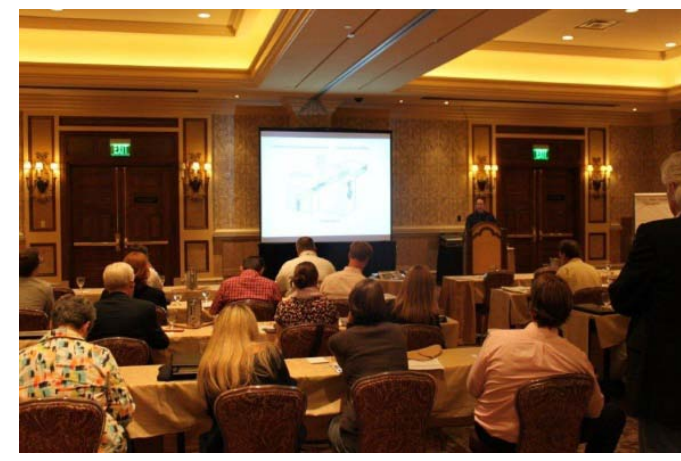

Figure 3. Deane Evans with BARA facilitates the afternoon discussion

- We need to provide contractors with tools to make the jump to selling and implementing energy efficiency strategies.

- Showing cost effectiveness is key. There is currently no good modeling tool that does this. If people start seeing the dollars right in front of them it will push the decision and push the market. A good tool needs to show cost effectiveness in simple "black and white" terms.

- An intelligent or informed consumer will help drive the adoption of energy efficiency.

- For motivation, we're all consumers and most people use social media personally. Best way to motivate people is through social media and through their peers.

- Homeowners are unaware or not interested because energy efficiency means nothing to them. Put an educated contractor in front of them walking through energy efficiency features and benefits and they get motivated.

- Consumers do not respond well to social media, call centers, or websites if not followed up by a knowledgeable person. Remodelers need to be the army to talk to consumers.

- Create a message and leverage it many ways.

- 3-D visual tools could be incorporated into sales tools to show consumers what's happening inside their houses in spaces that they can't see.

- Fastest way to adoption is to show remodelers how they can make a buck and show consumers how they can save a buck and marry those two together.

- Word of mouth is the best marketing tool and social media is the new word of mouth.

HOW TO DO IT/WHY TO DO IT: How do remodelers actually create energy efficient remodels and what is the underlying building science that warrants doing it.

- A misinformed contractor is worse than someone who doesn't even try or care.

- Good content is good content.

- We're all comfortable in our silos and our industry. We do what we do. Get energy efficiency knowledge to remodelers so they feel comfortable getting outside of their silo. 
- What are the right mechanisms or blend of media to use to communicate building science information?

- Media choice is driven by content and intent.

- Information needs to be curated.

- We need to use whatever it takes to communicate to remodelers, not new media or specific types of media but whatever is appropriate.

THE MEDIA AND THE MESSAGE: Does content trump format or does format shape content?

- There is a core need to look at audiences and audience segmentation.

- New and traditional media strategies aren’t just relevant to remodelers but also to utilities, state energy offices, etc.

- The remodeling market is very fragmented and hard to reach. Remodelers get information from very specific places - their dealer, for example. Distribution centers and supply centers are a key vehicle.

- Content should drive the medium and appropriate content should be very targeted to the topic and audience.

- Major organizations should be a trusted messenger. In some communities, DOE could be a trusted messenger.

- Building America can be the trusted source.

- Asset packages that include many different assets to use with specific audiences should be created. You can't focus efforts just on one asset type because there are uses for many of them, depending on audience and intent. They all have to be available.

- People try what they see other people do. That's where social media can be the trigger for this - once they see others do it and they need to know where to go to get and know more information. They need to know they can trust that information.

- How do you get the information to the remodelers that don't pay attention or read? Speak to the remodeler, not to the engineers. Simplify the information.

- Trying to control content on the Internet is like trying to stop a river with a tennis racket.

- Trying to create new channels for information is more effort than is necessary; simply utilize existing channels and point to sources.

- No one will just dive into the existing Building America content. People like to "surf, snorkel, and dive" and we need to give the audience the first two options.

- Utilize graphics to catch interest and capture key points then use them to jump off into more detail.

- Seems like we're missing a website that would be conducive for remodelers, general contractors, and homeowners who want information but won't read a report. Cover all building science systems because once you have that website and that resource all those pieces can feed other uses and partners to promote deeper information. 


\section{Next Steps}

What emerged from the expert meeting is that the motivation to transform old buildings into more energy efficient ones has to come from being able to sell that transformation, both to the remodelers and to their clients. Once that case is made convincingly, remodelers need the resources to understand what to do and the building science that supports what they are doing. These messaging goals can be well served by new media in conjunction with more traditional media, but the content must be credible, concise, and engaging. This points to an opportunity for Building America to gather and/or create such content and provide it to the remodeling world.

The BARA team used the findings from this expert meeting to craft an evaluation tool that looks at the motivation behind being or becoming a remodeler that makes homes more efficient, the information format choices remodelers make, the content areas they are looking to for support, and their take on using video to learn. The results of this survey will help the BARA team further define the effective use of new media to help remodelers transform the country's existing housing stock into more energy efficient dwellings. 


\section{Appendix A: Invitation}

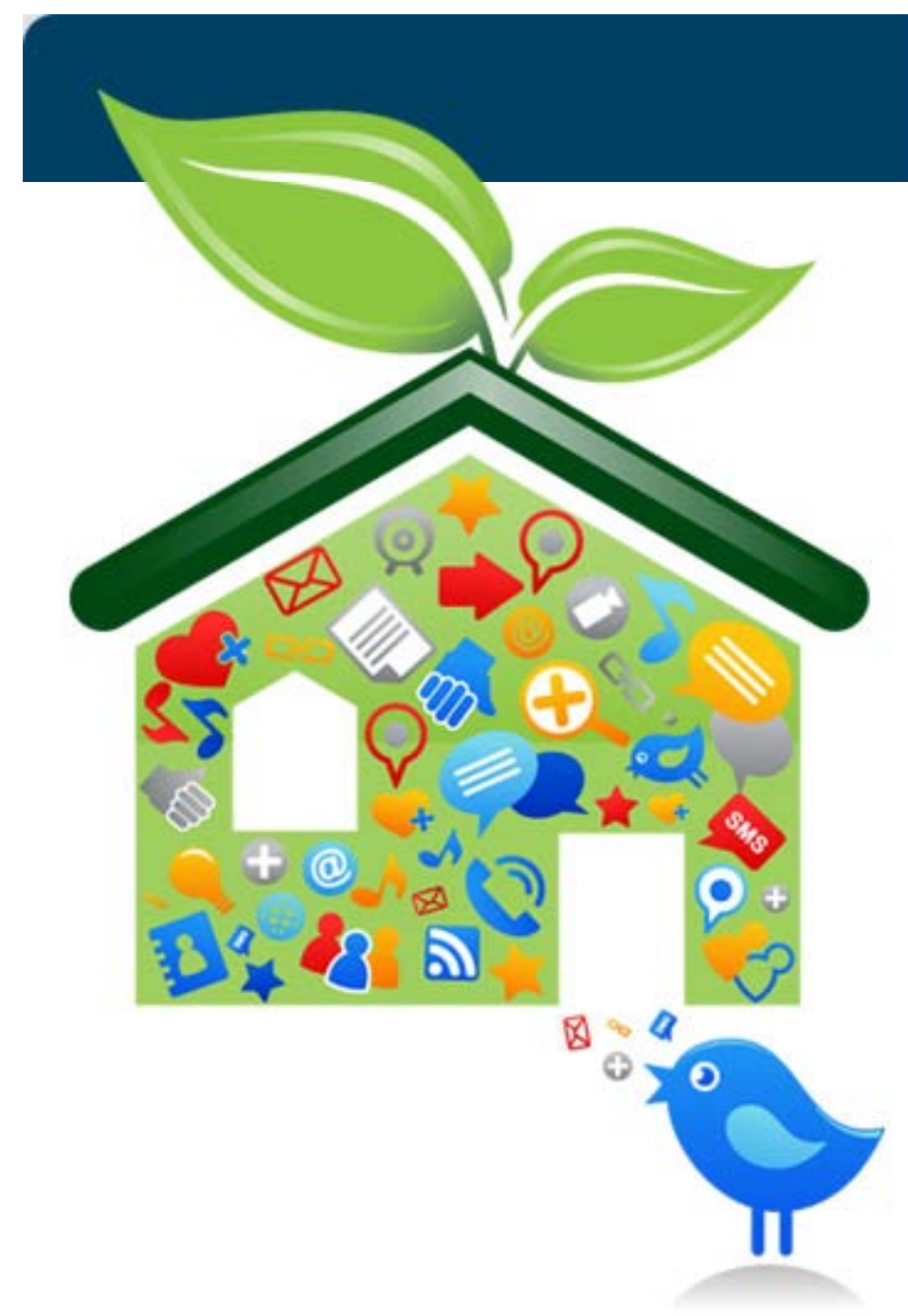

You're Invited!

On behalf of the Retrofit Alliance, a Building America team, we invite you to Transforming Existing Buildings through New Media: an Idea Exchange, to be held September 13, 2011 in Las Vegas, NV.

September 13, 2011 Green Valley Ranch, La Cascada I \& II

\section{Paseo Verde Parkway Henderson, NV 89052}

This workshop will bring together experts in the areas of communications, technology, education, and new media to explore opportunities to change the face of energy efficiency in existing homes.

Participate with us as we explore opportunities to transform the remodeling industry and radically improve residential energy performance in the next decade through new media strategies.

\section{Morning working session}

Morning working session (9:00am-3:30pm, EEBA conference location) will include key presenters from new and traditional media organizations, focused on strategies being employed (in residential remodeling industry and out) to create awareness, education, or change. Our core focus is to answer one question - how can new media strategies fast-track the adoption of energy efficiency in existing housing? This event is by invitation only. 


\section{Demonstration Feedback Session}

Demonstration feedback session (3:30pm-5:00pm, Green Valley Ranch, La Cascada I \& II) will focus on demonstrating specific technologies and surveying attendees. This event will be open to all EEBA attendees.

\section{Background}

New media - from social networks to online, on-demand training to apps and games - is transforming learning and working across the country at a rapidly accelerating pace. The "new" in new media constantly shifts. Fifteen years ago, the Internet, which gave us hypertext as a way to "drill down" and explore non-linear modes of learning, was completely new. Since then, the forms of online media have grown increasingly dynamic, incorporating video, animation, and sound in ways that have profoundly enhanced the visual and aural literacy of the world's wired populace. With digital video and photography as a primary mode of capture, and the Internet as a means of distribution, the ability to record and communicate visual data is now accessible to anyone, regardless of age or background, instantaneously. This alone has transformed society at every level, including the designers, builders and remodelers of America's housing stock. None of us could work the way we do today without online technologies, and the advancement of the use of technology in everyday life - work and personal - is not slowing its pace.

The BARA Team recognizes that emerging online technologies offer new opportunities to the U.S. Department of Energy's (DOE) Building America program, providing a means not only to deploy project research results to the public, but also as a means of gathering data from a much broader sampling range of active building projects than may not otherwise have been feasible.

The Building America Retrofit Alliance (BARA) is convening New Media for Existing Buildings: An Idea Exchange an "expert meeting" of thought leaders the field of multimedia content delivery - to better understand how new media might be used to transform the energy efficiency of existing buildings.

The goal is to explore - in a relatively free-ranging forum - what the new media landscape looks like going forward and how that might impact how the residential retrofit industry works, learns and adopts new methods and technologies. 


\section{Appendix B: Agenda}

\section{AGENDA}

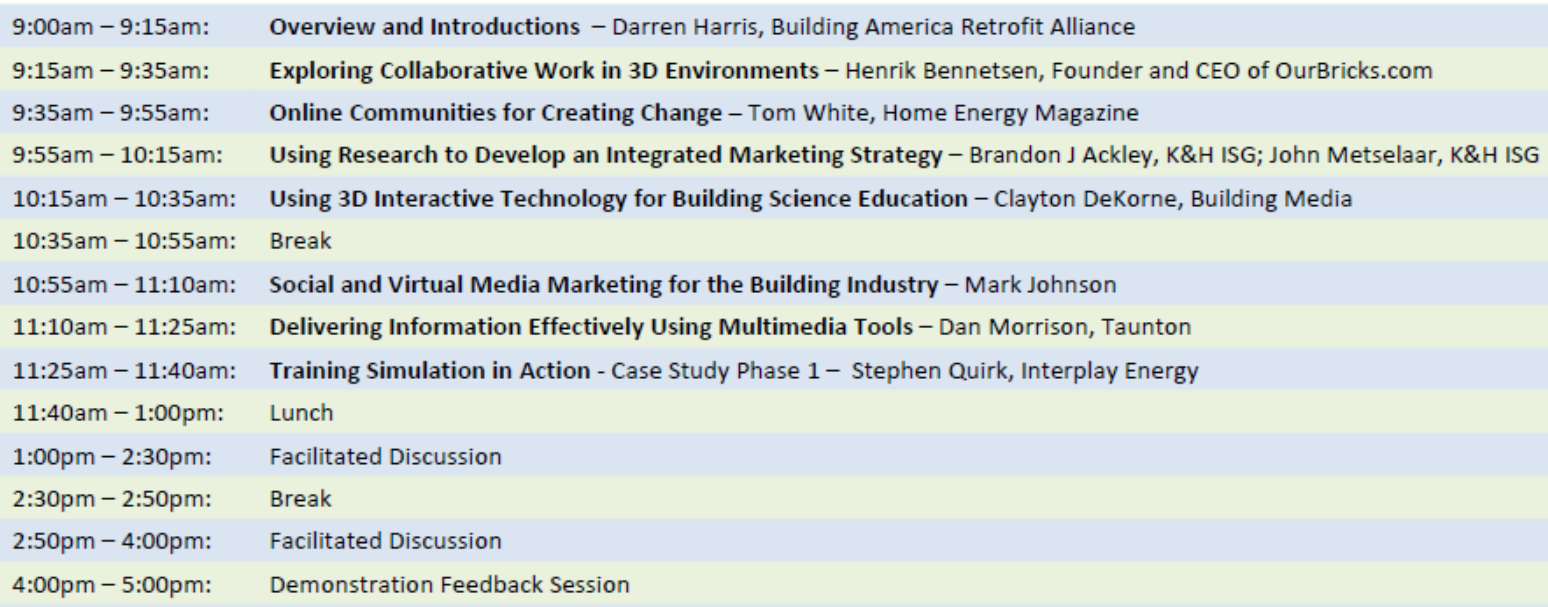


buildingamerica.gov

\section{U.s. DEPARTMENT OF Energy Efficiency \& ENERCY Renewable Energy}

